\title{
THE NATURAL EVOLUTION OF HIATAL HERNIAS
}

\author{
BY \\ EMILIO ROVIRALTA \\ From Instituto Policlinico, Barcelona, Spain
}

(RECEIVED FOR PUBLICATION MAY 1, 1963)

Observations made over the past 20 years at the Instituto Policlinico, Barcelona, on hiatal hernia have shown that the condition tends to spontaneous anatomical improvement, and that even if this does not occur a stomach partially or wholly displaced into the chest can function satisfactorily. This confirms the highly important teaching of Carré, Astley and Smellie (1952), and leads us to believe that many unnecessary operations are performed on these cases.

In many of our cases the records are incomplete, owing to the difficulty of following their progress over periods of as much as 20 years, and some of them have been operated upon and consequently have to be omitted from this study. So we shall discuss 10 cases only, dividing them into two groups, according to the extent of the displacement. It should be noted that several were selected for conservative treatment because their condition was too poor or the hernia too large to make surgery safe.

\section{Group 1: Total and Sub-total Hernias}

Case 1. J.P., male, presented at 6 weeks old, weight 4,250 g., had only a small part of the pyloric antrum remaining in the abdomen. There was persistent vomiting, frequently with blood, usually clotted. Red cells numbered $3,100,000$, with little variation in successive counts. There were no dark stools (Fig. 1a and $b$ ). At 8 months of age, in spite of conventional treatment, there was an exacerbation of symptoms and he was prepared for an operation. However, the parents objected, and we prescribed the erect position. At 10 months he improved, but he weighed only 6,100 g. All symptoms disappeared progressively until at 18 months he appeared cured. He was not examined again until he was $9 \frac{1}{2}$ years old. In the interval he vomited only when he had a respiratory infection, and there was never blood in the vomit; dysphagia was never present. A radiograph (Fig. 1c and d) showed that only the pylorus was in the abdomen, with very rapid stomach evacuation; but in spite of this anatomical abnormality he was clinically well.

Case 2. S.G.B., male, presented at 10 months, weighing $3,000 \mathrm{~g}$. Vomiting was persistent from 2 months of age, and was frequently bloody. His

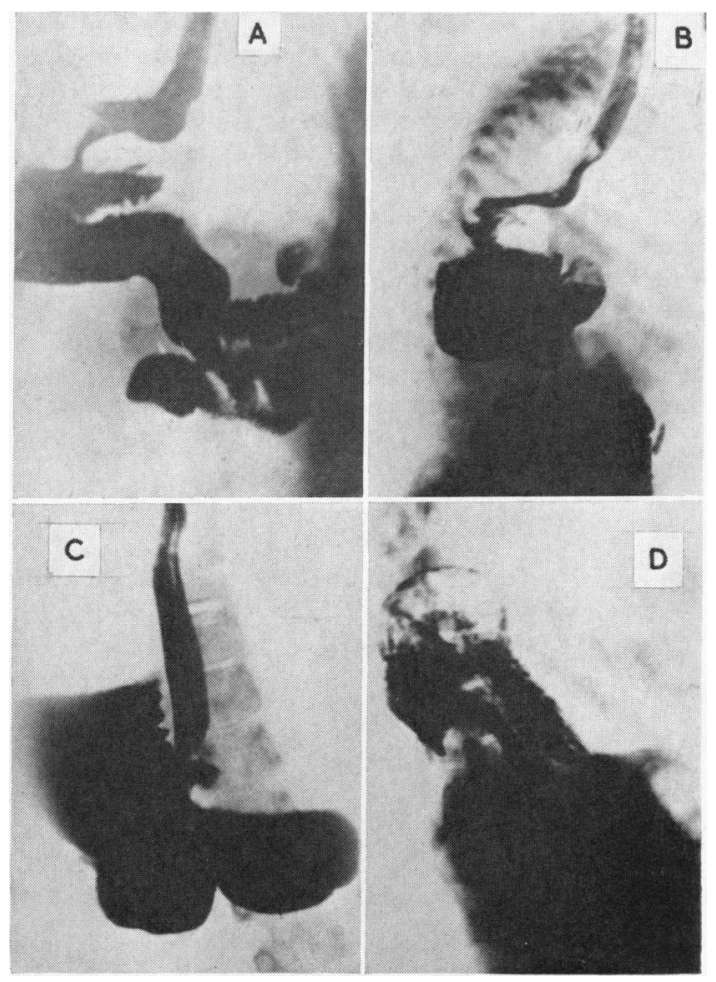

FIG. 1.-Case 1: (A) Radiograph, antero-posterior view at 6 weeks. (B) Lateral view, same age. (C) Antero-posterior view at 9 years and 6 months of age. The oesophagus is notably elongated, but the cardia remains in the thorax. (D) Lateral view at same age. Stomach notably descended, although still in the thorax. 


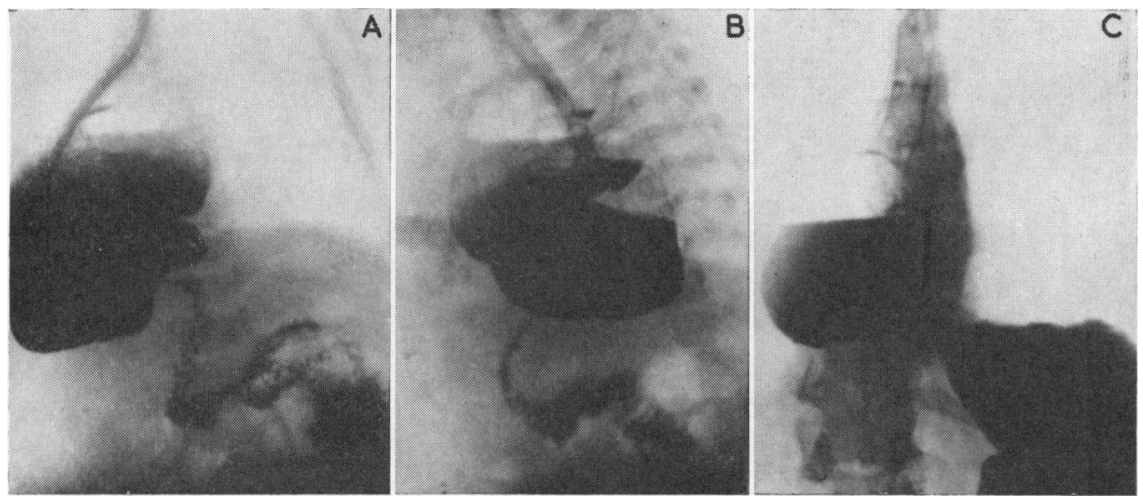

Fig. 2.-Case 2: (A) and (B) Stomach completely in the thorax at 10 months of age. (C) Less than one-third of stomach in the thorax at 21 years of age.

general condition was poor; there were no dark stools. Radiographs showed that the stomach was in the thorax (Fig. 2a and b). Under conservative treatment he showed slow improvement. At 14 months of age there was very little vomiting. At 16 months he weighed just $5,500 \mathrm{~g}$. and at 19 months, 5,400 g. From then on, there was a gradual disappearance of symptoms with frequent gastric lavages so that the mother no longer considered it necessary to return for medical consultation. We saw him again at 21 years of age. He had not had treatment for 19 years, during which he followed a not very active life. He was not allowed to work and exhibited strange behaviour. His appetite was good. He was thin but with normal muscular development and height. The radiographs show less than one-third of the stomach in the abdominal position (Fig. 2c), but in spite of the slightness of the anatomical improvement he was clinically cured.
Case 3. R.M.R., female, presented at 7 months, weighing $7,700 \mathrm{~g}$. She had vomited since birth and blood clots were frequently present. At 3 months of age (with no treatment, due to lack of diagnosis) she had improved spontaneously. When she was first seen, a radiograph showed that more than three-quarters of the stomach was in the right hemithorax above the diaphragm (Fig. 3a and b). Since it was impossible for her to retain the test meal, the film was taken with a tube in the stomach. Red cells numbered 5,900,000.

She improved rapidly under treatment, and was not examined again until the age of 21 , at our request. Without treatment she had been absolutely symptomfree during 20 years. There was good psychological development. A radiograph shows the stomach in the normal position. The Hiss angle was satisfactory and no reflux was seen in the Trendelenburg position. The cardiac folds of the mucosa were normal (Fig. 3c).
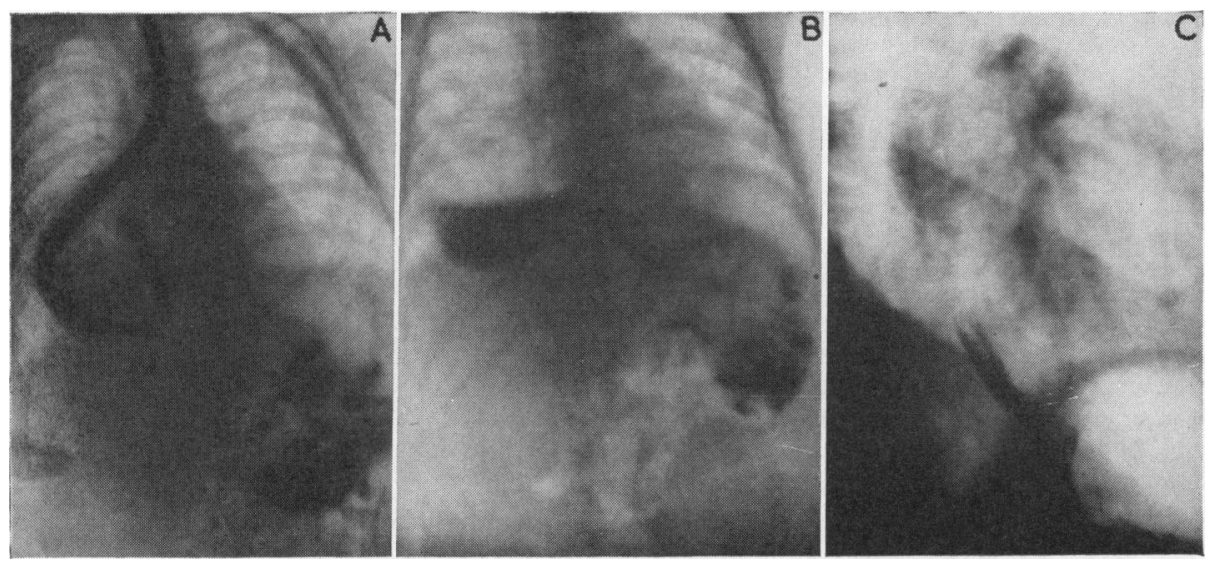

Fig. 3.-Case 3: (A) and (B) Most of the stomach in the thorax at 7 months of age. (C) Stomach completely in the abdominal cavity at 21 years of age; a good Hiss angle. No reflux in the Trendelenburg position. 
Case 4. P.A., a male, presented at 9 months. He had vomited from the first day after birth; it was sometimes greenish in colour, but showed no blood. There was intense tympanism; later, enterocolitis. Radiological examination showed almost complete intrathoracic stomach (Fig. 4). Slight improvement following postural and complementary treatment (not always carried out at home) during two months, after which we did not see him again until the age of $17 \frac{1}{2}$ years, when he reported no complaints during the interval. Present weight $62.5 \mathrm{~kg}$., height 1.71 metres. He refused an X-ray examination for fear, he said, of finding out the whole truth about his stomach; consequently the present anatomy is unknown though he is clinically cured.

\section{Group 2: Small and Medium-sized Hernias}

Case 5. R.B., female, aged 7 months, had vomited from birth, frequently with blood. Radiograph showed one-quarter of the stomach above the diaphragm, pointing to the right (Fig. 5). She improved in a few months under postural treatment. Not examined again till the age of 16 , at which time she said there had been no treatment in the interval and that there had been complete disappearance of all symptoms at the age of 11 . Recently she began to have an occasional dark vomitus. She works, lives a normal life and never had dysphagia. There is good psychosomatic development. Radiographs show the whole stomach in the abdomen.

Case 6. M.E.M., female, presented at 6 months. At 8 days of age she began to vomit copiously, frequently

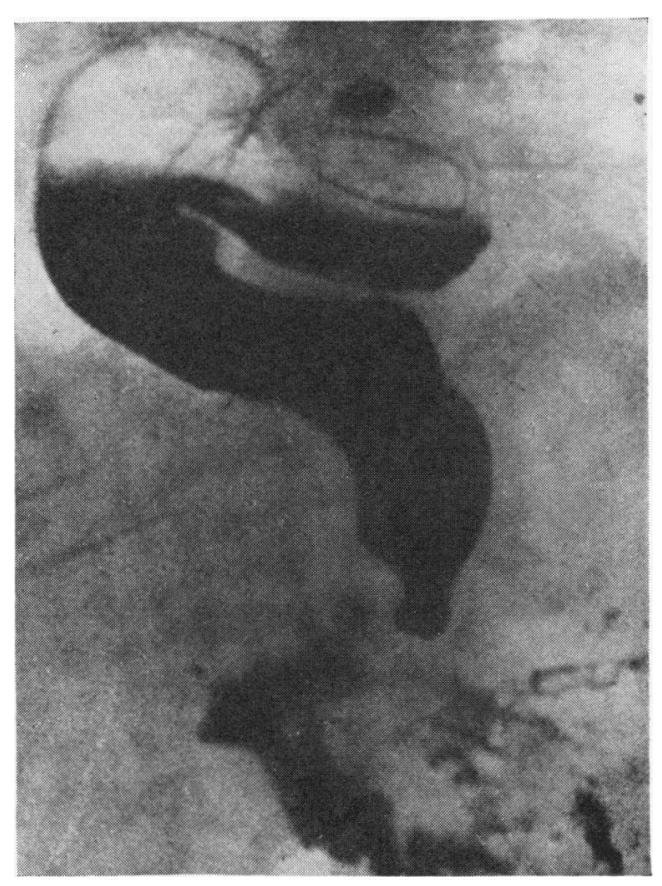

Fig. 4.-Case 4: Stomach almost completely in the thorax at 9 months of age.

with blood. There were no dark stools. Weight 6,600 g. Radiograph showed small stomach hernia

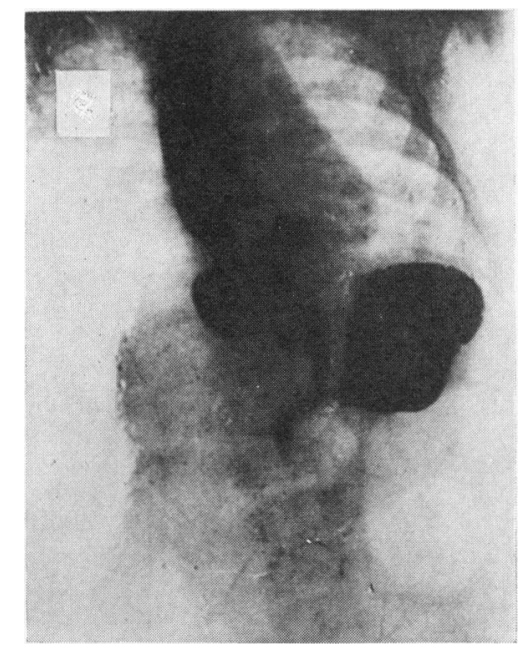

Fig. 5.-Case 5: At 7 months of age; one-third of the stomach is above the diaphragm. 


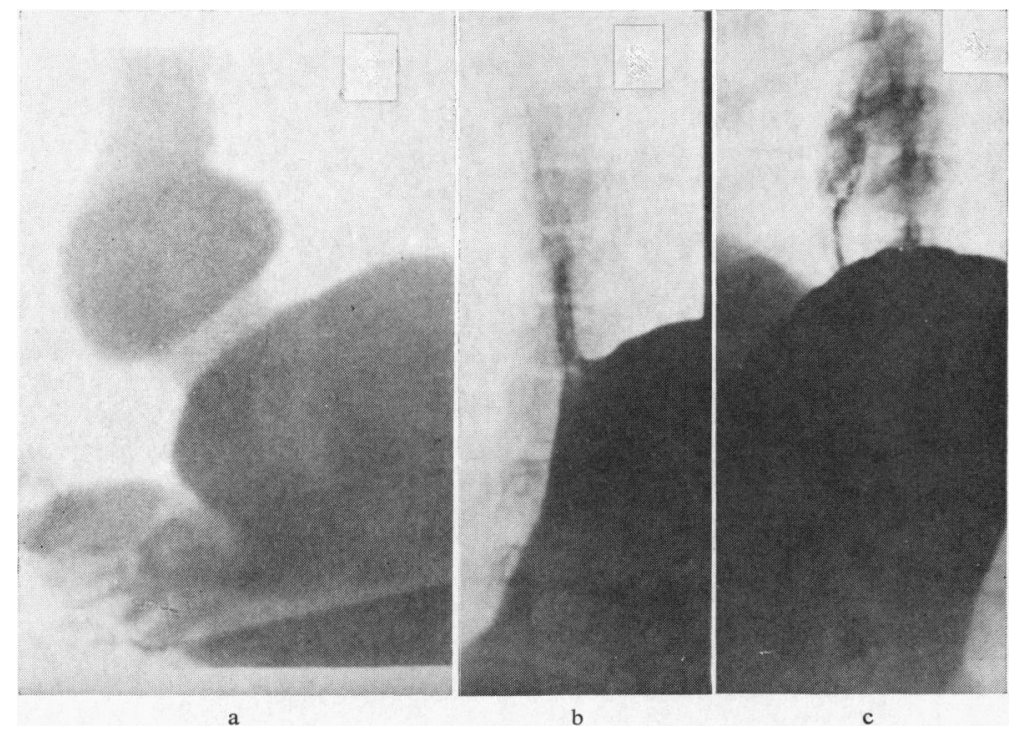

Fig. 6.-Case 6: (a) At 5 months, small hernia.

(b) Disappearance of the hernia at 5 years and 9 months.

(c) No reflux in the Trendelenburg position.

(Fig. 6a). There was rapid improvement under postural treatment. At 2 years of age there were occasional symptoms. She never had dysphagia. At $5 \frac{1}{2}$ years she was in good condition. Radiograph shows the whole stomach in the abdomen; a good Hill angle. She leads a normal life (Fig. $6 \mathrm{~b}$ and c).

Case 7. J.B.S., a male, aged 8 months, had vomited from birth with blood. There were no dark stools. At 4 months he was diagnosed as having pyloric stenosis
(Fig. 7a). One-third of the stomach was in the thorax and there were indications of typical pyloric stenosis. With postural treatment there were very good results up to the age of 15 months. Then there was relapse and pylorotomy was performed with good results. At $8 \frac{1}{2}$ years one-sixth of the stomach was in the thorax (Fig. $7 \mathrm{~b}$ and c). He is now clinically cured.

Case 8. A.S.P., female, 9 months, had vomited since birth; this had been bloody from the fourth month. She

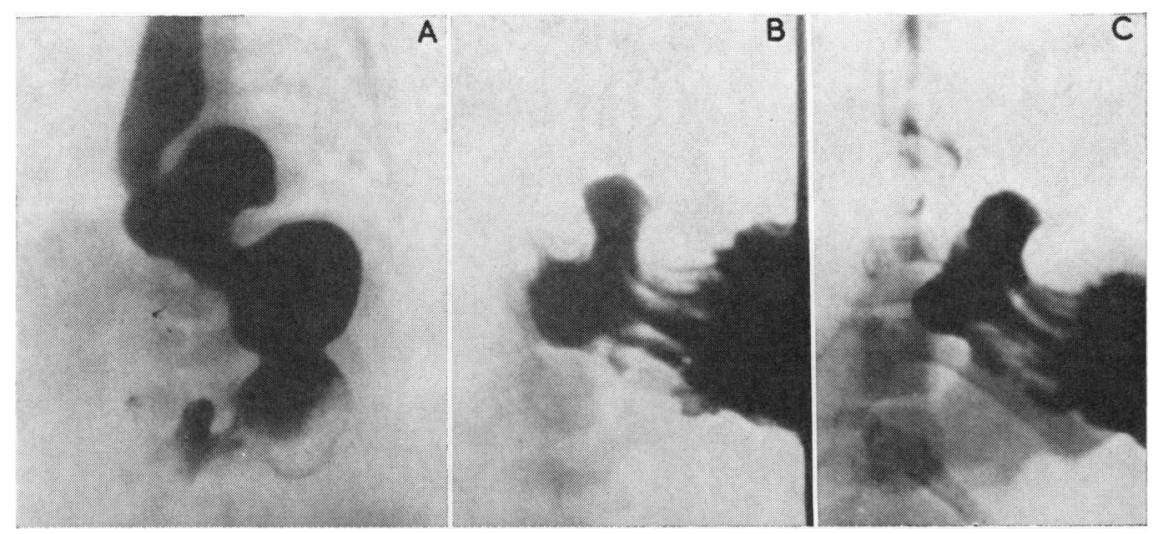

FIG. 7.-Case 7: (A) At 8 months, one-third of the stomach is in the thorax. Elongation of the pyloric canal typical of pyloric stenosis. Pylorotomy at the age of 15 months. (B) and (C) Reduction of the hernia to one-sixth of the stomach at 8 years of age. 
improved under postural treatment. Half of the stomach was above the hiatus and to the right (Fig. 8a). At $3 \frac{1}{2}$ years of age there were no symptoms; treatment was discontinued. There was a very small hernia (Fig. 8b), and at 11 years there were no complaints. Radiograph shows small intrathoracic hernia, small ectopia (Fig. 8c).

Case 9. M.M., female, age 1 month, had vomited since birth immediately after feeding, and when older there was late vomiting also. Blood was never seen in vomit or stools. Radiographs showed hiatus hernia of about two-thirds of the stomach volume (Fig. 9). Under adequate treatment she showed slow improvement with relapses. At 12 years, parents wrote from a distant city stating that she enjoyed a symptom-free normal life. The anatomical result is of course not known.

Case 10. E.G., a male, age 1 month, had vomited from birth. There was obvious discomfort after feedings. His weight was $3,500 \mathrm{~g}$. at birth and $2,900 \mathrm{~g}$. at 1 month. With postural treatment improvement was so rapid that radiographs were not taken. He was seen again at 9 months when his mother reported one more instance of vomiting with red stripes in the vomitus. His weight was $6,400 \mathrm{~g}$. Radiographs showed more than one-quarter of the stomach within the thorax (Fig. 10). When placed in the sitting position he showed rapid improvement with a weight gain of $450 \mathrm{~g}$. in a month. He stopped attendance at 10 months of age. He was

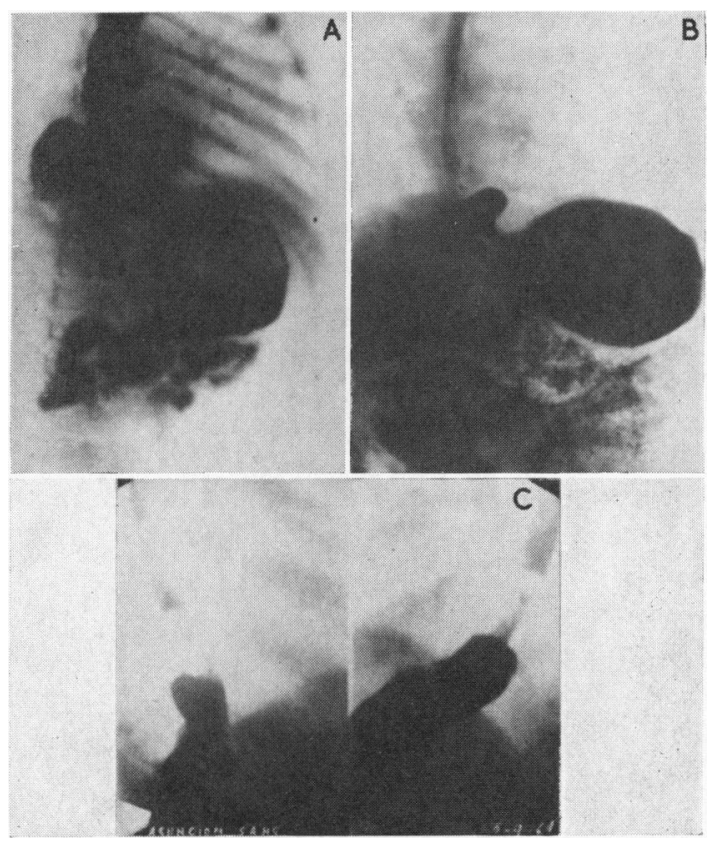

Fig. 8.-Case 8: (A) At 9 months, more than half of the stomach is: above the diaphragm. (B) At 6 years and 6 months, the hernia is notably reduced. (C) At 11 years of age, there is an occasional 'flash' image of gastric ectopy.

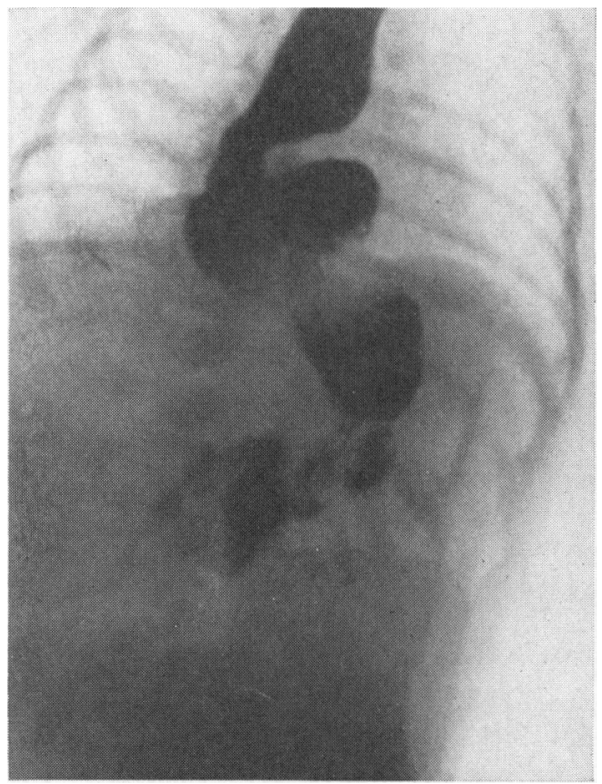

Fig. 9.

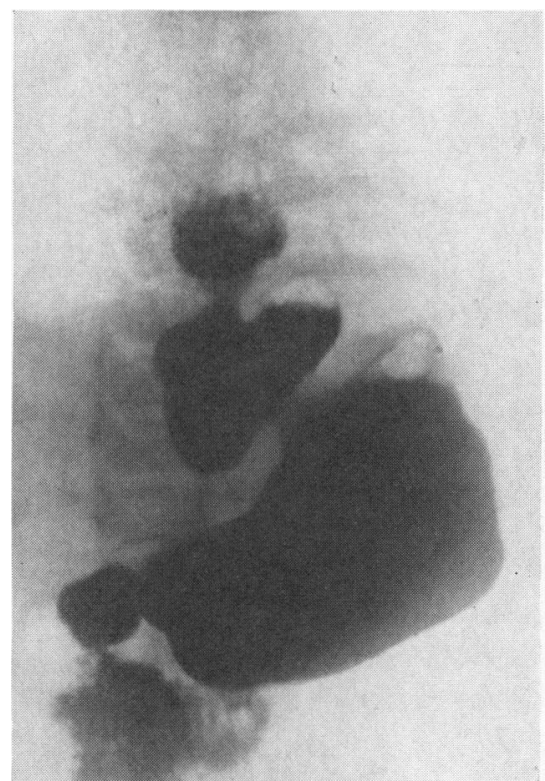

Fig. 10.

FIG. 9.-Case 9 at 1 month. Two-thirds of the stomach is in the thorax.

Fig. 10.-Case 10 at 1 month. More than one-quarter of the stomach is in the thorax. 
re-examined at $6 \frac{1}{2}$ years when he was clinically normal, and so the parents refused x-ray examination.

\section{BIBLIOGRAPHY}

Astley, R. and Carré, I. J. (1954). Gastro-oesophageal incompetence in children. Radiology, 62, 351 .

Carré, I. J. (1959). The natural history of the partial thoracic stomach (hiatus hernia) in children. Arch. Dis. Childh., 34, 344. (1960). Postural treatment of children with a partial thoracic stomach (hiatus hernia). ibid., 35, 569.

and Astley, R. (1958). The gastro-oesophageal junction in infancy; $A$ combined cineradiographic and manometric study. Thorax, 13, 159.

- (1960). The fate of the partial thoracic stomach ('hiatus hernia') in children. Arch. Dis. Childh., 35, 484.
- - and Smellie, J. M. (1952). Minor degrees of partial thoracic stomach in childhood; Review of 112 cases. Lancet, $2,1150$.

Findlay, L. and Kelly, A. Brown (1931). Congenital shortening of the oesophagus and the thoracic stomach resulting therefrom. J. Laryng. 46,797 .

Katsch, G. (1943). Hernia del hiato esofágico. In Tratado de Medicina Interna.-III; 1a part, p. 381, ed. G. Bergmann, E. von Staehelim and V.'Salle. Editorial Labor S.A., Barcelona, Madrid, Buenos Aires and Rio de Janeiro.

Kelly, H. D. Brown (1953). In discussion on hiatus hernia and oesophagitis. Proc. roy. Soc. Med., 46, 943.

Plarre F. E. (1956). Gastro-oesophageal reflux in infancy and childhood. Med. J. Aust., 2, 249.

Roviralta, E. (1960). Contribucion al estudio de las pequeñas malformaciones cardio-esofagicas. Rev. esp. Pediat., 16, 39.

- (1961). Ectopia gastrica parcial y hernia gastrica por el hiato esofagico. Rev. esp. Enferm. Apar. dig., 20, 1. 